\title{
Exploration of Encapsulated Modified Psyllium Husk for Preparation of Probiotic Basundi
}

\author{
H.W. Deshpande, S.D. Katke, S.A.S. Hashmi
}

10.18805/ajdfr.DR-1674

\begin{abstract}
Background: The dairy industry is one of the largest industries in India. The exports were made to 105 countries in the world. Dairy production is one of the major sustenance factors for the rural economy of India. Notably, India ranks first in Isabgol production (98\%) and is the sole supplier of seeds and husk in the international market. Among medicinal plants, Isabgol is the first ranked foreign exchange earner for the country. India is the largest producer and the main supplier of seed and husk to the world market. It contains a significant number of proteins and husk yields colloidal mucilage which are valued for medicinal application and is used in Ayurveda, unani and allopathic systems of medicines. It is the main constituent of a number of laxative preparations. The psyllium is high in soluble fibre content with detoxing effect over digestive system makes it a very apt nutraceutical. Basundi is one of the heats desiccated indigenous products popular in Western part of India, mostly Maharashtra and Gujarat. It can be classified in the condensed milk group along with rabri, khoa, mithai and kheer and can be considered similar to sweetened condensed whole milk.

Methods: The present investigation indicates utilization of encapsulated lactic acid bacteria culture (Lactobacillus acidophilus, Lactobacillus bulgaricus) and modified psyllium husk for the preparation of probiotic basundi. The prepared probiotic basundi was analyzed for sensorial, physicochemical and microbial quality parameters. Probiotic basundi was prepared from $1000 \mathrm{ml}$ of milk, 90 gm sugar, 02-03 pieces of cardamom, saffron and encapsulated LAB culture having $\left(10^{7}, 10^{8}\right.$ and $10^{9} \mathrm{cfu} / \mathrm{gm}$ containing equal proportions of Lactobacillus acidophilus and Lactobacillus bulgaricus) with 0.65 per cent hydrochloric acid modified psyllium husk. The probiotic basundi was then stored at refrigerated conditions at $4^{\circ} \mathrm{C}$ for $08 \mathrm{hrs}$.

Result: The organoleptic evaluation of probiotic basundi was carried out. As per the score of hedonic scale, basundi with encapsulated 10 per cent probiotic culture $\left(10^{9} \mathrm{cfu} / \mathrm{gm}\right)$ with 0.65 per cent hydrochloric acid modified psyllium husk had shown maximum consumer acceptability (8.3) among all samples.
\end{abstract}

Key words: Encapsulation, Lactobacillus acidophilus, Lactobacillus bulgaricus, Lactic acid bacteria, Probiotic basundi, Psyllium husk.

\section{INTRODUCTION}

The dairy industry is one of the largest industries in India. The exports were made to 105 countries in the world. Dairy production is one of the major sustenance factors for the rural economy of India. At the national level, about 17 per cent of the total value of output from agriculture derives from this sector contributing about 8 per cent to Gross Domestic Product and placing Indian milk sector in first place (Samal and Pattanaik, 2014).

Notably, India ranks first in Isabgol production (98\%) and is the sole supplier of seeds and husk in the international market. Among medicinal plants, Isabgol is the first ranked foreign exchange earner for the country. India is the largest producer and the main supplier of seed and husk to the world market. USA is the chief importer of Isabgol seeds and husk. It contains a significant amount of proteins and husk yields colloidal mucilage which are valued for medicinal application and is used in Ayurveda, unani and allopathic systems of medicines. It is the main constituent of a number of laxative preparations containing sodium bicarbonate and various flavors used in modern medicine. In India Gujarat and Rajasthan states are the major producer states of psyllium. Psyllium husk is obtained from genus Plantago. The psyllium is high in soluble fiber content with detoxing effect over digestive system makes it a very apt nutraceutical.
Department of Food Microbiology and Safety, College of Food Technology, Vasantrao Naik Marathwada Krishi Vidyapeeth, Parbhani431 402, Maharashtra, India.

Corresponding Author: H.W. Deshpande, Department of Food Microbiology and Safety, College of Food Technology, Vasantrao Naik Marathwada Krishi Vidyapeeth, Parbhani-431 402, Maharashtra, India. Email: hemantd22@gmail.com

How to cite this article: Deshpande, H.W., Katke, S.D., Hashmi, S.A.S. (2021). Exploration of Encapsulated Modified Psyllium Husk for Preparation of Probiotic Basundi. Asian Journal of Dairy and Food Research. DOI: 10.18805/ajdfr.DR-1674.

Submitted: 07-04-2021 Accepted: 02-07-2021 Online: 11-09-2021

Plantago ovata commonly known as 'Psyllium' in English and 'Isabgol' in Hindi belongs to the family of Plantaginaceae, is a $10-45 \mathrm{~cm}$ short-stemmed annual herb known by different names such as ashwagolam, aspaghol, aspagol, blond Psyllium. Isabgol has high fiber content and acts like a sponge serving to clean the bowels and is extensively cultivated in many parts of the globe. It is commercially an important Rabi season crop known for its medicinal properties. Apart from its husk (The seed coat is known as "husk") it is also being 
used in food industry especially in ice creams, biscuits and candies. The crop is mainly cultivated in the states of Rajasthan, Gujarat, Haryana and Madhya Pradesh.

Basundi is one of the heats desiccated indigenous products popular in Western part of India, mostly Maharashtra and Gujarat. It can be classified in the condensed milk group along with rabri, khoa, mithaiand kheer and can be considered similar to sweetened condensed whole milk (Raghavan and Kumar, 1960). Basundi has special importance in various festivals and celebration. Basundi is an important indigenous desiccated whole milk product prepared by partial dehydration of the milk with sugar. The dehydration of the milk is done in a karahi on direct fire. The original volume of milk is reduced to about 40 to 50 per cent. Basundi is mostly served on ceremonial occasions at feasts and festivals. The market value of product depends upon a relative thick creamy consistency, white to light brown colour, sweetish caramel aroma and soft textured flakes uniformly distributed throughout the product mass (Gaikwad et al., 2015).

Lactic acid bacteria are the most well-known and widely used probiotic bacteria. The lactic acid bacteria are grampositive, usually non- motile, non-sporulating, catalase negative, cocci or rods. They produce lactic acid as a sole product of fermentative metabolism of carbohydrate substrates. Most lactobacillus species are homo fermentative, producing mainly lactic acid as metabolic by product but some are hetero fermentative i.e., they produce ethanol, $\mathrm{CO}_{2}$ as well as lactate respectively. Thus, to fulfill the nutritional requirement of probiotic bacteria, prebiotics plays a major role. Probiotics are mainly carbohydrates by nature. According to $\mathrm{FAO} / \mathrm{WHO}$ the definition of prebiotics is, "non digestible substances that provide a beneficial physiological effect on the host by selectively stimulating the favorable growth or activity of a limited number of indigenous bacteria".

Encapsulation is a mechanical or physicochemical process that traps a potentially sensitive material and provide a protective barrier between it and the external conditions. The various encapsulation technique includes extrusion, spray drying, spray cooling, lyophilization, emulsion etc. Extrusion is the oldest and most common technique to produce capsule with hydrocolloids. Microencapsulation is the process of encasing an active component in a shell and is defined as a technology of packaging solids, liquids or gaseous materials in miniature, sealed capsules that can release their contents at controlled rates under the influences of specific condition. From microbiological point of view, microencapsulation can be defined as the process of entrapment, enclosure of cells of microorganisms by means of coating them with proper hydrocolloid(s) in order to isolate the cells from the surrounding environment, in a way that results in appropriate cell release in the intestinal medium. (Jayalalitha, 2013).

\section{MATERIALS AND METHODS}

The study was carried out at Department of Food Microbiology and Safety, College of Food Technology, VNMKV, Parbhani, Maharashtra during academic year 2019-2020.

\section{Procurement of raw materials}

Psyllium husk, buffalo milk, fresh cream sugar, cardamom and saffron were purchased from local market.

\section{Starter culture}

The probiotic organisms viz. Lactobacillus acidophilus and Lactobacillus bulgaricus were individually grown in MRS broth at $37^{\circ} \mathrm{C}$ for $48 \mathrm{hrs}$. The cultivated MRS broth was then centrifuged at $4000 \mathrm{rpm}$ for $10 \mathrm{~min}$ to harvest the cells. The harvested cells were washed twice with sterile water. The biomass was taken as starter culture.

Flow Sheet 1. Preparation of starter culture Stock culture $\downarrow$

Activation of bacterial strains in MRS broth separately at $37^{\circ} \mathrm{C}$ for $48 \mathrm{hrs}$

$$
\downarrow
$$

MRS broth containing desired strains

$$
\downarrow
$$

Centrifugation at $4000 \mathrm{rpm} / 10 \mathrm{~min}$ $\downarrow$

Biomass (Starter culture)

\section{Encapsulation of probiotics}

The microencapsulation of probiotic bacteria was performed using the extrusion technique. Extrusion method is the oldest and most common procedure of producing hydrocolloid capsules (King, 1995). It is a simple and cheap method with gentle operations which makes cell injuries minimal and causes relatively high viability of probiotic cells. Biocompatibility and flexibility are some of the other specifications of this method (Klein et al., 1983; Tanaka et al., 1984). Hydrocolloid solution was prepared by using a combination of sodium alginate and guar gum at 1 and 0.8 per cent $(w / v)$ respectively, $10 \mathrm{ml}$ of inoculum $(5 \mathrm{ml}$ each of $L$. acidophilus and L. bulgaricus) was mixed in $2 \mathrm{gm}$ of modified psyllium husk powder. Probiotic culture and modified psyllium husk powder normal mixed properly and passed through a syringe in the form of droplets into $0.3 \mathrm{M}$ calcium chloride solution. Interaction between the two solutions led to formations of beads $(2-5 \mathrm{~mm})$ and the resulting beads were then stored in 0.1 per cent peptone (Karthikeyan et al., 2014).

\section{Flow sheet 2. Microencapsulation of Strains}

Preparation of polymer solution

$$
\downarrow
$$

Addition of probiotic culture and modified psyllium husk powder

$$
\downarrow
$$

Extrusion of the cell- polymer solution into calcium chloride solution

$$
\downarrow
$$

Capsule formation by cross linking

$$
\downarrow
$$

Recovery of capsule and storage in 0.1 per cent peptone solution at $4^{\circ} \mathrm{C}$ 


\section{Acid modification of psyllium husk}

Acid modification of psyllium husk was carried out as per the method described by Xiaoyin Pei (2008) with certain changes in concentration of $\mathrm{HCl}$ in ethanol solvent as per the results of the research study conducted by the Syed et al., (2018) on the standardization of acid concentration and solvent ratio for modification of psyllium husk. Hence, acid modification with concentration of 0.65 per cent $\mathrm{HCl}$ in the ethanol solvent for solvent ratio of $1: 6(\mathrm{w} / \mathrm{v})$. Solvent ratio was carried out to improve functional properties of psyllium husk as required for exploration in the value addition of processed food products. The solvent used for psyllium husks treatment was vacuum filtered, rinsed with 95 percent ethanol and 100 percent for 2 times each, then dried and stored. Control group was treated with 100 percent ethanol and followed the steps of preparation as in Table 1.

\section{Standardization of probiotic basundi preparation}

The processing methodology standardized by using organoleptic evaluation. The recipe used for preparation of probiotic basundi is mentioned below in Table 2 .

\section{Preparation of basundi}

The basundi was prepared as per standard described by (Gite et al., 2017). Fresh, clean buffalo milk was boiled in iron pan, with constant stirring cum scraping action. When concentration was about one half of original volume of milk, clean, good quality sugar was added @ 5 per cent of original volume of milk, gentle heating was continued for five minutes till final concentration of about $2: 1$, basundi was then allowed to boil for 10 minutes. Then pan was removed from fire and allowed to cool. The product was then cooled and stored at refrigeration temperature till use.

\footnotetext{
Flow sheet 3. Preparation of basundi

Receiving milk (buffalo milk) $\downarrow$

Filtration$$
\downarrow
$$

Standardization of milk ( 6 per cent fat) $\downarrow$

Heating at simmering temperature $\left(80-90^{\circ} \mathrm{C}\right)$ $\downarrow$

Vigorously stirring-cum-scraping $\downarrow$

Addition of sugar ( 6 per cent of milk) $\downarrow$

Gentle heating for 5 minutes $\downarrow$

Cooling to room temperature $\downarrow$

Storage at refrigeration temperature $\left(4^{\circ} \mathrm{C}\right)$ $\downarrow$

Basundi
}

\section{Preparation of probiotic basundi with encapsulation}

Preparation of probiotic basundi with encapsulated strains, inoculum at 10 per cent of the final basundi was encapsulated modified psyllium husk with probiotic beads and the beads were aseptically added to $100 \mathrm{gm}$ basundi. The probiotic basundi was then stored at refrigerated conditions to $\left(4^{\circ} \mathrm{C}\right.$ for $5 \mathrm{hrs}$ ). The standard recipe with different viable counts of culture is mentioned below in Table 3 .

\section{Flow Sheet 4. Probiotic basundi with Encapsulation Basundi \\ Washing of the probiotic beads} $\downarrow$

Addition of encapsulated modified psyllium husk with probiotic beads $\downarrow$

Incubation at $37^{\circ} \mathrm{C}$ for $5 \mathrm{hrs}$ $\downarrow$

Storage $\underset{\downarrow}{\left(4^{\circ} \mathrm{C} / 8 \mathrm{hrs}\right)}$

Probiotic basundi

\section{RESULTS AND DISCUSSION}

Acid modification of psyllium husk was carried out as per the method described by Xiaoyin Pei (2008) with certain changes in concentration of $\mathrm{HCl}$ in ethanol solvent as per the results of the research study conducted by the Syed et al. (2018) on the standardization of acid concentration and solvent ratio for modification of psyllium husk (Plantago ovata F.) i.e. The solvent used for psyllium husks treatment was ethanol with 34-37 per cent hydrochloric acid $(\mathrm{HCl})$ at the concentration level of $0.65 \%(w / v)$. Hence, further studies were conducted to investigate the effects of selected acid solvent ratios at reaction temperature of $37.5^{\circ} \mathrm{C}$ on physical, chemical and functional properties of the acid treated psyllium husk samples. At reaction temperature of $37.5^{\circ} \mathrm{C}$ psyllium husk-solvent ratios (PSH:Solvent @ $1: 6(\mathrm{w} / \mathrm{v}))$ was tested. After the desired time completion of $48 \mathrm{hrs}$ for specified acid concentration and PSH and acid solvent ratio. The acid treated psyllium husk product was recovered by vacuum filtration.

Table 1: Acid treatment levels for psyllium husk.

\begin{tabular}{lc}
\hline $\begin{array}{l}\text { Concentration } \\
\text { of } \mathrm{HCl} \text { in ethanol }\end{array}$ & $\begin{array}{c}\text { Psyllium husk (PSH) } \\
\text { solvent ratio }\end{array}$ \\
\hline $0.65 \%$ & $1.6(\mathrm{w} / \mathrm{v})$ \\
$0 \%$ for control & $1.6(\mathrm{w} / \mathrm{v})$ \\
\hline
\end{tabular}

Table 2: Standard recipe for preparation of probiotic basundi.

\begin{tabular}{lc}
\hline Ingredients & Quantity $(\mathrm{g} / \mathrm{ml})$ \\
\hline Milk & 1000 \\
Sugar & 90 \\
Cardamom and Saffron & $02-03$ pieces \\
\hline
\end{tabular}


It can be observed from Table 4 that psyllium husk was having white or pale buff colour. It is evident from the data that the psyllium husk was having translucent and thin boat shaped free flowing flakes broken into smaller fragments in appearance with bland mucilaginous taste and odourless in flavour. It is clear from the Table 4 that psyllium husk was having total ash content $2.60 \pm 0.03 \mathrm{w} / \mathrm{w}$ and insoluble ash content $0.28 \pm 0.004 \mathrm{w} / \mathrm{w}$ with swell volume of $40.50 \mathrm{ml} / \mathrm{gm}$. The results revealed that loss in water, light and heavy extraneous matter were $7.21 \pm 0.02 \mathrm{w} / \mathrm{w}, 4.95 \pm 0.03 \mathrm{w} / \mathrm{w}$ and $1 \pm 0.03 \mathrm{w} / \mathrm{w}$ respectively. Similar results were reported by Syed et al., (2018). It is revealed from Table 5 that iron

Table 3: Standardization of recipe with different viable counts of cultures.

\begin{tabular}{lcc}
\hline Samples & Inoculum \% & Viable count (cfu/g) \\
\hline MK & 0 & 0 \\
A & 10 & $10^{7}$ \\
B & 10 & $10^{8}$ \\
C & 10 & $10^{9}$ \\
\hline
\end{tabular}

MK - Milk basundi without culture addition.

A - Basundi + encapsulated modified psyllium husk with 10 percent probiotic culture having $\left(10^{7}\right) \mathrm{cfu} / \mathrm{gm}$.

B - Basundi + encapsulated modified psyllium husk with 10 percent probiotic culture having $\left(10^{8}\right) \mathrm{cfu} / \mathrm{gm}$.

C - Basundi + encapsulated modified psyllium husk with 10 percent probiotic culture having $\left(10^{9}\right) \mathrm{cfu} / \mathrm{gm}$.

Table 4: Quality characteristics of psyllium husk.

\begin{tabular}{lc}
\hline Parameters & Results \\
\hline Colour & White or pale buff \\
Appearance & Translucent \\
Taste & Bland Mucilaginous \\
Flavour & Odourless \\
Total ash $(\mathrm{w} / \mathrm{w})$ & $2.60 \pm 0.03$ \\
Acid insoluble ash $(\mathrm{w} / \mathrm{w})$ & $0.28 \pm 0.004$ \\
Swell volume $(\mathrm{ml} / \mathrm{gm})$ & 40.50 \\
Loss on drying $(\mathrm{w} / \mathrm{w})$ & $7.21 \pm 0.02$ \\
Light extraneous matter $(\mathrm{w} / \mathrm{w})$ & $4.95 \pm 0.03$ \\
Heavy extraneous matter $(\mathrm{w} / \mathrm{w})$ & $1 \pm 0.03$ \\
\hline
\end{tabular}

Table 5: Mineral composition of native psyllium husk.

\begin{tabular}{lc}
\hline Parameters & Results $(\mathrm{mg} / 100 \mathrm{~g})$ \\
\hline Iron $(\mathrm{Fe})$ & $7.99 \pm 0.01$ \\
Copper $(\mathrm{Cu})$ & $0.672 \pm 0.04$ \\
Manganese $(\mathrm{Mn})$ & $0.600 \pm 0.001$ \\
Zinc $(\mathrm{Zn})$ & $0.322 \pm 0.002$ \\
\hline
\end{tabular}

and copper content of native psyllium husk was found to be $7.99 \pm 0.01 \mathrm{mg} / 100 \mathrm{~g}$ and $0.672 \pm 0.04 \mathrm{mg} / 100 \mathrm{~g}$ respectively while manganese and zinc content was found to be $0.600 \pm$ $0.001 \mathrm{mg} / 100 \mathrm{~g}$ and $0.322 \pm 0.002 \mathrm{mg} / 100 \mathrm{~g}$. Iron content was found highest among the minerals assessed. The results are in good agreement with the results reported by Syed et al., (2018).

It is revealed from the Table 6 that the hydration capacity of psyllium husk was decreased with the acid concentration treatment from 3.0 to $1.6 \mathrm{ml} / \mathrm{g}$. Substantial decrease in hydration capacity was observed in case of $\mathrm{PSH}$ sample treated with 0.65 per cent acid concentration having lowest $1.6 \mathrm{ml} / \mathrm{g}$ while control sample having $2.8 \mathrm{ml} / \mathrm{g}$. It can be observed from the Table 6 that the oil absorption capacity of 0.65 percent acid treated psyllium husk for the $\mathrm{PSH}$ : solvent ratio @ 1:6 was found to be lowest as $0.5 \mathrm{ml} / \mathrm{g}$, indicating that the OAC of treated psyllium husk decreased with the acid treatment from $1.0 \mathrm{ml} / \mathrm{g}$ (native PSH) to $0.5 \mathrm{ml} /$ g. According to Oladele and Aina (2007), the major chemical component affecting OAC is protein, which is composed of both hydrophilic and hydrophobic parts. Higher OAC might be due to the partial denaturation of proteins with exposition of high hydrophobic proteins which show superior binding to hydrocarbon chains of lipids. The effects of psyllium husk - solvent ratio (1:6) and acid concentration on the water uptaking rate of psyllium samples was also investigated at a reaction temperature of $37.5^{\circ} \mathrm{C}$. The data from the Table 6 indicates that the water up-taking rate is lowest for 0.65 percent acid treated psyllium husk for the $\mathrm{PSH}$. solvent ratio @ 1:6 sample as $1.63 \mathrm{mg} /(\mathrm{g} \times \mathrm{min})$. Moreover, substantial water up-take rate reduction was observed between the raw psyllium husk sample and PSH treated with 0.65 per cent acid concentration for PSH. solvent ratio @ 1:6 as 2.22 mg/ $(\mathrm{g} \times \mathrm{min})$ and $1.63 \mathrm{mg} /(\mathrm{g} \times \mathrm{min})$ respectively. The data for the water up-taking rate showed that acid treatment of $\mathrm{PSH}$ at 1:6@ $@$ PSH. solvent ratio highly affects the water up-taking rate, particularly it helps in reduction of water up-taking rate of the psyllium husk. The results for the water up-taking rate are in good agreement with the results found by the Xiaoyin Pei (2008), Liangli Yu (2000) and Zhihong et al., (2009) for water up-taking rate for acid treated PSH. Similar results were also reported by Syed et al. (2018).

It can be observed from Table 7 that moisture content increased from 7.15 to 7.32 percent upon acid modification. Fat content decreased after acid modification from 1.82 to 0.63 per cent while protein content decreased from 2.91 to 1.20 per cent. Similarly, ash and crude fibre decreased from 2.61 to 2.23 and 3.10 to 2.65 per cent respectively. The decrease in fat, protein, ash and crude fibre content resulted

Table 6: Effect of acid modification on functional properties of psyllium husk.

\begin{tabular}{lcccc}
\hline $\begin{array}{l}\text { Concentration of } \\
\mathrm{HCl} \text { in ethanol }\end{array}$ & $\begin{array}{c}\text { Psyllium husk: } \\
\text { Solvent ratio }\end{array}$ & $\begin{array}{c}\text { Hydration } \\
\text { capacity }(\mathrm{ml} / \mathrm{g})\end{array}$ & $\begin{array}{c}\text { Oil absorption } \\
\text { capacity }(\mathrm{ml} / \mathrm{g})\end{array}$ & $\begin{array}{c}\text { Water up-taking } \\
\text { rate }[\mathrm{mg} /(\mathrm{g} \times \mathrm{min}]\end{array}$ \\
\hline Control & $1: 6$ & 2.8 & 0.8 & 1.88 \\
$0.65 \%$ & $1: 6$ & 1.6 & 0.5 & 1.63 \\
Native psyllium husk & - & 3.0 & 1.0 & 2.22 \\
\hline
\end{tabular}


due to the partial degradation of the psyllium gel hardness because of acid modification. Further, carbohydrate content increased from 86.48 to 88.95 per cent and energy value decreased from 371 to $366 \mathrm{Kcal} / 100 \mathrm{~g}$. The results are in good agreement with results reported by Syed et al. (2018). The results from the Table 7 also indicates that Dietary fibre and Arabinoxylan contents as $75.59 \pm 0.26$ and 46.20 \pm 0.21 percent for native psyllium husk while for acid modified psyllium husk $77.65 \pm 0.82$ and $47.80 \pm 0.48$ percent respectively. The results are in good agreement with results reported by Syed et al. (2018). Slight increase in dietary fibre might be due to marginal increase in the total carbohydrate content resulting from the sugar hydrolysis giving by products such as oligosaccharides, and possibly along with acid salts that may form by reaction of psyllium husk components or other reaction by products as reported by the Liangli Yu (2000) in the Patent No. W01999062342 A9. The acid modified psyllium husk degraded on the external surface structure only due to hydrolysis occurred by excursion, that's why dietary fibre did not affect by the acid treatment. Considering psyllium husk as source of dietary fibre some researchers inferred

Table 7: Effect of acid modification on proximate composition of psyllium husk.

\begin{tabular}{lcc}
\hline Parameters (\%) & $\begin{array}{c}\text { Native } \\
\text { psyllium husk }\end{array}$ & $\begin{array}{c}\text { Modified } \\
\text { psyllium husk }\end{array}$ \\
\hline Moisture & 7.15 & 7.32 \\
Fat & 1.82 & 0.63 \\
Protein $(\mathrm{N} \times$ 6.25) & 2.91 & 1.20 \\
Ash & 2.61 & 2.23 \\
Carbohydrate & 86.48 & 88.95 \\
Crude fibre & 3.10 & 2.65 \\
a) Dietary fibre & $75.59 \pm 0.26$ & $77.65 \pm 0.82$ \\
b) Arabinoxylan & $46.20 \pm 0.21$ & $47.80 \pm 0.48$ \\
Energy value $(\mathrm{Kcal} / \mathrm{100 \textrm {g } )}$ & $371 \mathrm{Kcal} / 100 \mathrm{~g}$ & $366 \mathrm{Kcal} / 100 \mathrm{~g}$ \\
\hline
\end{tabular}

Table 8: Sensory evaluation of the prepared encapsulated probiotic basundi.

\begin{tabular}{lccccc}
\hline Samples & Colour & Flavour & Taste & Texture & $\begin{array}{c}\text { Overall } \\
\text { acceptability }\end{array}$ \\
\hline MK & 8.0 & 8.0 & 8.0 & 8.0 & 8.0 \\
A & 7.9 & 7.3 & 7.2 & 7.2 & 7.4 \\
B & $\mathbf{8 . 8}$ & $\mathbf{8 . 3}$ & $\mathbf{8 . 5}$ & $\mathbf{8 . 4}$ & $\mathbf{8 . 3}$ \\
C & 7.9 & 7.6 & 7.9 & 7.7 & 7.7 \\
SE \pm & 0.018 & 0.104 & 0.122 & 0.132 & 0.122 \\
CD at 5\% & 0.054 & 0.345 & 0.406 & 0.438 & 0.406 \\
\hline
\end{tabular}

that arabinoxylan as the active fraction helpful to manage various physiological ailments (Fischer et al., 2004; Saghir et al., 2008; Van-Craeyveld et al., 2008). Guo et al. (2008) explored the chemistry of psyllium husk and noted total carbohydrates up to 84.98 per cent considering as dietary fibre.

It is evident from the Table 8 that among various sensory characteristics color, flavor and taste were significantly affected by the various levels encapsulated modified psyllium husk with probiotic culture i.e., Lactobacillus acidophilus and Lactobacillus bulgaricus ranging from $10^{7}$ to $10^{9} \mathrm{cfu} / \mathrm{gm}$ and its incubation time period $5 \mathrm{hrs}$. and after freezing. The sample B obtained higher score for overall acceptability (8.3) as compared to control and other sample. Gaikwad et al., (2015) reported the sensory scores for flavor, body and texture and color and appearance and sensorial characterization of ujani basundi and basundi are $8.29 \pm 0.86,8.32 \pm 0.86,8.64 \pm 0.93$ and $8 \pm 0.93,8.1 \pm 1.43,7.9 \pm 1.43$ respectively for ujani basundi and basundi.

The observations in respect of acidity of probiotic basundi as influenced by addition of encapsulated modified psyllium husk with probiotic beads. The results in this investigation were comparable with the Gaikwad and Hembade (2012) who reported the moisture content of ujani basundi was 54.60 per cent data showed in Table 9 revealed that the probiotic basundi sample Moisture (53.90 per cent), Fat (10.85 per cent), Protein (7.5 per cent), Carbohydrates (28.3 per cent), Ash (1.56 per cent) .Acidity ( 0.42 per cent) and Total solid (50.02 per cent). The results were found to be close in agreement with the study conducted by Sonalika Srivastava et al., (2015). The moisture is noted to be in increasing the addition of probiotics beads from 53.90 in control to 51.03 in sample. Fat content of probiotics beads added basundi is reduced compared to that of control sample without the addition of psyllium. It was observed that the carbohydrate content of prepared probiotic basundi was 28.3 percent in sample. (Yadav, 2015). These results are comparable with the results reported by Patel and Upadhyay (2003).

A minimum range of $10^{7}-10^{8}$ plate microorganisms per gram or milliliter should be present in food product in order to meet the requirements of a probiotic food, as by the Japanese Fermented Milk and Lactic Acid Bacteria Drinks Association (Ishibashi and Shimanura, 1993). It is evident that viable counts were observed at dilutions rate of $10^{7}, 10^{8}$ and $10^{9}$ (Table 10)

The results from Table 11 shows that, the basundi sample was free from Coliform and $E$. coli when the sample

Table 9: Physico-chemical characteristics of probiotic basundi.

\begin{tabular}{|c|c|c|c|c|c|c|c|}
\hline \multirow{2}{*}{ Samples } & \multicolumn{2}{|c|}{ Physical parameters } & \multicolumn{5}{|c|}{ Chemical parameters } \\
\hline & $\begin{array}{c}\text { Total Solid } \\
\%\end{array}$ & $\begin{array}{l}\text { Acidity } \\
(\%)\end{array}$ & $\begin{array}{c}\text { Moisture } \\
(\%)\end{array}$ & $\begin{array}{l}\text { Fat } \\
(\%)\end{array}$ & $\begin{array}{c}\text { Protein } \\
(\%)\end{array}$ & $\begin{array}{c}\text { Carbohydrate } \\
(\%)\end{array}$ & $\begin{array}{l}\text { Ash } \\
\text { (\%) }\end{array}$ \\
\hline Control & 46.11 & 0.38 & 51.03 & 12.03 & 9.02 & 27.25 & 1.77 \\
\hline Probioticbasundi & 50.02 & 0.42 & 53.90 & 10.85 & 7.05 & 28.32 & 1.56 \\
\hline
\end{tabular}


Table 10: Viable counts (LAB) of probiotic basundi during storage.

\begin{tabular}{lccc}
\hline \multirow{2}{*}{ Time in (Days) } & \multicolumn{3}{c}{ Viable counts } \\
\cline { 2 - 4 } & (cfu/gm) $\times 10^{7}$ & $(\mathrm{cfu} / \mathrm{gm}) \times 10^{8}$ & $(\mathrm{cfu} / \mathrm{gm}) \times 10^{9}$ \\
\hline 0 & 3.3 & 2.1 & 1.5 \\
2 & 4.1 & 2.6 & 1.9 \\
4 & 4.6 & 2.9 & 2.1 \\
6 & 4.9 & 3.0 & 2.1 \\
\hline
\end{tabular}

Table 11: Microbial quality of probiotic basundi during storage.

\begin{tabular}{lccc}
\hline $\begin{array}{l}\text { Time in } \\
\text { (Days) }\end{array}$ & $\begin{array}{c}\text { Total plate count } \\
(\mathrm{cfu} / \mathrm{g}) \times 10^{7}\end{array}$ & $\begin{array}{c}\text { Yeast and mold } \\
(\mathrm{cfu} / \mathrm{g}) \times 10^{4}\end{array}$ & $\begin{array}{c}\text { Coliform } \\
\text { count }\end{array}$ \\
\hline 0 & 2.9 & $\mathrm{ND}$ & $\mathrm{ND}$ \\
2 & 3.9 & 2.6 & $\mathrm{ND}$ \\
4 & 4.1 & 2.0 & $\mathrm{ND}$ \\
6 & 5.2 & 1.4 & $\mathrm{ND}$ \\
\hline
\end{tabular}

was fresh and throughout the storage period of 06 days at refrigerator temperature as result of good hygienic and sanitary conditions, during the preparation.

\section{CONCLUSION}

Probiotic basundi was prepared from $1000 \mathrm{ml}$ of milk, 90 gm sugar, 02-03 pieces of cardamom, saffron and encapsulated $L A B$ culture having $\left(10^{7}, 10^{8}\right.$ and $10^{9} \mathrm{cfu} / \mathrm{gm}$ containing equal proportions of Lactobacillus acidophilus and Lactobacillus bulgaricus) with 0.65 per cent hydrochloric acid modified psyllium husk. The probiotic basundi was then stored at refrigerated conditions at $4{ }^{\circ} \mathrm{C}$ for $08 \mathrm{hrs}$. The organoleptic evaluation of probiotic basundi was carried out. As per the score of hedonic scale, basundi with encapsulated 10 per cent probiotic culture $\left(10^{9} \mathrm{cfu} /\right.$ gm) with 0.65 percent hydrochloric acid modified psyllium husk had shown maximum consumer acceptability (8.3) among all samples.

\section{REFERENCES}

Fischer. M.H., Yu, N., Gray, G.R., Ralph, J., Anderson, L. and Marlett, J.A. (2004). The gel-forming polysaccharide of psyllium husk (Plantago ovata Forsk). Carbohydrates Research. 339: 2009-2017.

Gaikwad, S.M. and Hembade, A.S. (2012). Studies on process standardization of cow milk ujani basundi. Journal of Animal Production Advances. 2(1): 52-5

Gaikwad, A.S., Chavan K.D. and More K.D (2015). Preparation of fibre fortified basundi using date fruit (Phoenix diactylifera). Journal of Nutrition and Health Sciences. 3(3): 304.

Gite, A.S, More D.R. and Satwadhar P.N. (2017). Development and standardization of custard apple basundi. Journal of Pharmacognosy and Phytochemistry. 6 (5): 1170-1172.

Guo, Q., Cui, S.W., Wang, Q. and Young, J.C. (2008). Fractionation and physico-chemical characterization of psyllium gum. Carbohydrate Polymers. 73 (1): 35-43.

Ishibashi, N. and Shimanura, S. (1993). Bifidobacteria: research and development in Japan. Journal of Food Technology. 47: 126.
Jayalalitha, V. (2013). Microencapsulation of probiotics to prepare functional dairy products. Probiotics in Sustainable Food Production: Current Status and Future Prospects Probiotic Foods. pp. 12-21.

Karthikeyan, N., Elango, A., Kumaresan, G., Gopalakrishnamurty, T.R. and Raghunath, B.V. (2014). Enhancement of probiotic viability in ice cream by microencapsulation. International Journal of Science Environment and Technology. 3(1): 339-347.

King, A.H. (1995). Encapsulation of food ingredients: A review of available technology, focusing on hydrocolloids. In: Risch, S.J., Reineccius, G. A., eds. Encapsulation and Controlled Released of Food Ingredient. ACS Sym Ser 590. Washington, DC: American Chemical Society. pp. 26-41.

Klein, J., Stock ,J. and Vorlop, K.D. (1983). Pore size and properties of spherical ca-alginate biocatalysts. European Journal of Applied Microbiology and Biotechnology. 18: 86-91.

Liangli, Yu. (2000). Acid and solvent modification of psyllium. Patentee WO1999062342 A9.

Oladele, A. and Aina, J. (2007). Chemical composition and functionalproperties of flour produced from two varieties of tigernut (Cyperus esculentus). African Journal of Biotechnology. 6 (21): 2473-2476.

Patel, H.G. and Upadhyay, K.G. (2003). Standardization of compositional recipe of Basundi - level of sugar addition. Journal of Food Science and Technology. 40 (1): 89-92

Raghavan, D. and Kumar K (1960). Glossary of Indian dairying terms. First Indian Dairy Book, Publication Indian Council of Agriculture Research. New Delhi, 101-102.

Saghir, S., M.S. Iqbal, M.A. Hussain, Koschella, A. and Heinze, T. (2008). Structure characterization and carboxymethylation of arabinoxylan isolated from Ispaghula (Plantago ovata) seed husk. Carbohydrate Polymers. 74: 309-317.

Samal, L. and Pattanaik, A.K (2014). Dairy production in India: Existing scenario and future prospects. International. Journal of Livestock Research. 4 (2): 105-113.

Sonalika Srivastava, et al. (2015). Studies on Utilization of buttermilk in chapati making. Int. J. Res. Emerg. Sci. Technol. 2 (10): 30-35

Syed, K.A., Syed, H.M., Deshpande, H.W. and Sawate, A.R. (2018). Standardization of acid concentration and solvent ratio for modification of psyllium husk (Plantago ovata $F$.). International Journal of Chemical Studies. 6 (2): 2318-2323.

Tanaka, H., Masatose, M. and Veleky, I.A. (1984). Diffusion characteristics of substrates in calcium-alginate beads. Biotechnology and Bio- engineering. 26: 53-58.

Van-Craeyveld, V.V., Delcour, J.A. and Courtin, C.M. (2009). Extractability and chemical and enzymic degradation of psyllium (Plantago ovata Forsk) seed husk arabinoxylans. Food Chemistry. 112: 812-819

Xiaoyin, P. (2008). Acid modification of psyllium. Associate Professor, Liangli (Lucy) Yu, Ph.D, Department of Nutrition and Food Science.

Yadav, K.S. (2015). Process Standardization of Fiber Enriched Basundi Using Carrot, Thesis submitted to Mahatma Phule Krishi Vidyapeeth, Rahuri-413 722, Dist. Ahmednagar, Maharashtra, India.

Zhihong, C., Jessica Blackford, Qin Wang, Liangli (Lucy) Y. (2009). Acid treatment to improve psyllium functionality. Journal of Functional Foods. 1(1): 44-49. 